\title{
O COMPORTAMENTO DA PRECIPITAÇÃO NO VERÃO 2013-2014 EM SÃO CARLOS/SP A PARTIR DA CLASSIFICAÇÃO DOS ANOS PADRÕES
}

\author{
Bruno César dos Santos ${ }^{(a)}$, Paulo Henrique de Souza ${ }^{(b)}$, Rafael Grecco Sanches ${ }^{(c)}$, Francisco \\ Arthur da Silva Vecchia ${ }^{(d)}$
}

(a) Laboratório de Climatologia e Conforto Térmico, Centro de Recursos Hídrico e Educação Ambiental (CRHEA), Escola de Engenharia de São Carlos (EESC), Universidade de São Paulo (USP). Email: bruno-unifal@ @otmail.com

(b) Instituto de Ciências da Natureza (ICN), Universidade Federal de Alfenas (UNIFAL-MG). Email: phsouza31@hotmail.com

(c) Laboratório de Climatologia e Conforto Térmico, Centro de Recursos Hídrico e Educação Ambiental (CRHEA), Escola de Engenharia de São Carlos (EESC), Universidade de São Paulo (USP). Email: rafagsanches@ usp.br

(d) Laboratório de Climatologia e Conforto Térmico, Centro de Recursos Hídrico e Educação Ambiental (CRHEA), Escola de Engenharia de São Carlos (EESC), Universidade de São Paulo (USP). Email: fvecchia@ sc.usp.br

\section{Eixo: Climatologia em Diferentes Níveis Escalares: Mudanças e Variabilidades}

\begin{abstract}
Resumo
O Estado de São Paulo apresenta índices pluviométricos situados entre 1.200 e $1.600 \mathrm{~mm}$ com precipitação concentrada no período situado entre os meses de outubro a março. A passagem de frentes e o processo de frontogênese respondem pelo "input" hídrico. Dada a localização que possui (reverso das Cuestas Basálticas) o município de São Carlos apresenta índices pluviométricos ligeiramente superiores ao seu entorno devido a contribuição que recebe das chuvas orográficas. No verão iniciado em 2013 (outubro) e encerrado em 2014 (março), todo Sudeste, assim como essa área específica sofreu com a diminuição das precipitações ocasionadas por mudanças no padrão atmosférico da América do Sul. Atentando para isso, o presente estudo procurou analisou a dinâmica atmosférica desse período chuvoso (Ano Hidrológico) de 2013/2014, descrevendo e caracterizando a dinâmica dos sistemas atmosféricos que nele atuaram e sua variação dentro dos padrões habituais que possuíam, através da metodologia da análise dinâmica.
\end{abstract}

Palavras chave: Atmosfera, Clima, Análise, Chuva, Seca.

\section{Introdução e Justificativa}

Os índices térmicos e pluviométricos, bem como sua intensidade e frequência ao longo do ano constituemse em alguns dos parâmetros que descrevem um tipo climático por representarem a manifestação concreta do padrão atmosférico que prevalece sobre uma determinada área. Obviamente esse comportamento atmosférico é definido e estabelecido após a análise dinâmica de suas variáveis climatológicas por um lapso de tempo considerável que permite a identificação dos seus padrões habituais. A compreensão desse funcionamento atmosférico é obtida através da climatologia dinâmica. Monteiro (1971) foi o precursor dessa área do conhecimento no Brasil estabelecendo a metodologia da análise rítmica e dos anos padrão, inaugurando uma nova forma de analisar e estudar a atmosfera. 
A climatologia dinâmica propõe que todos os atributos do clima, tais como massas de ar, pressão atmosférica, temperatura do ar, umidade relativa, radiação solar, precipitação, entre outros, sejam analisadas de maneira integrada, permitindo a visualização dos fenômenos temporais diários (SILVEIRA, 2006), ao contrário da climatologia clássica que se baseava apenas em valores médios de alguns desses atributos, tornando o resultado generalista, independente e unidimensional. Santos (2005) ressalta a aplicabilidade da análise dinâmica, destacando os benefícios que proporciona inclusive para as atividades agropecuárias ao permitir a compreensão precisa do papel que o ritmo climático possui no planejamento e produção das safras. Segundo Girão, Corrêa e Guerra (2006, p. 4) "a análise rítmica do clima e, especificamente, a caracterização do comportamento pluvial de uma área é de grande relevância para uma avaliação de sua suscetibilidade a riscos naturais".

No caso específico do Estado de São Paulo, é possível verificar nesses últimos anos (2013/2014) uma alteração significativa dos padrões de distribuição das chuvas, que pode mudar o caráter (seco ou chuvoso) de qualquer dado (mensal sazonal ou anual) levando a uma incerteza considerável no regime pluvial (FRANCA, 2014; GRABIEL; NUNES, 2014), pois, ao contrário do que costuma ocorrer nessa época do ano, poucos sistemas frontais conseguiram alcançar o Brasil, e, a Zona de Convergência do Atlântico Sul, responsável pelo escoamento de umidade da Amazônia para o Sudeste não ocorreu de maneira habitual (CENTRO DE PREVISÃO DO TEMPO E ESTUDOS CLIMÁTICOS - CPTEC, 2014). Isso diminuiu consideravelmente as chuvas, ao passo que contribuiu com o aumento da temperatura no Sul e Sudeste do Brasil, bem como com enchentes e inundações no Sul da Amazônia e Centro-Norte da Bolívia, desabrigando milhares de pessoas.

Como o processo de precipitação é fundamental para o ciclo hidrológico, o aumento de eventos excepcionais tem modificado a variabilidade das chuvas referente à intensidade, e principalmente, a distribuição espacial e temporal em um determinado local. Desta forma, o presente estudo procurou comparar os dados pluviais do período chuvoso (outubro a março) de 2013/2014, que corresponde aos meses de maiores índices de precipitação para região de São Carlos-SP para caracteriza-lo, segundo as premissas de ano habitual ou atípico, de acordo com a visão dinâmica do clima, de maneira a alcançar resultados representativos de sua realidade atual a partir de uma série histórica que forneça sua habitualidade e seus anos padrão.

\section{Conceituação e Fundamentação - Climatologia Clássica e Dinâmica}

A climatologia clássica analisa isoladamente cada elemento climático (temperatura, umidade, pressão atmosférica, precipitação, direção dos ventos, entre outros) debruçando-se sobre suas médias aritméticas. Com tal procedimento incorre na possibilidade de mascarar a verdadeira realidade climática, pois 
desconsidera a conexão que existe entre os elementos do clima, ignorando os valores extremos que podem apontar para alguma situação relevante que se encontra totalmente escondida pelo uso das médias que tornam os resultados uniformes e distantes da realidade (BORSATO, 2000). Sobre o ponto de vista geográfico, o método tradicional é incapaz de explicar o dinamismo dos fenômenos e suas verdadeiras sucessões de estados, pois os valores médios impossibilitam a compreensão da realidade destruindo a conexão existente com os demais elementos da superfície terrestre, forçando a climatologia geográfica a buscar novas formas de abordar o estudo do clima (BARROS; ZAVATTINI, 2009).

Diante dessa demanda, a climatologia dinâmica surge com objetivo fundamental de considerar os elementos climáticos de maneira integrada, possibilitando a compreensão de como se manifestam, e a identificação da sua ação fisiológica e ritmo. Quando Max Sorre definiu o complexo climático, concebeu a noção de ritmo, com a combinação dos elementos meteorológicos sobre um determinado lugar e, a sucessão dos tipos de tempo, regida por leis da meteorologia dinâmica, extraindo o conhecimento do mecanismo da variação do clima (SANT’ANNA NETO, 2008). Monteiro (1962, p.12) acreditava "na necessidade de recorrer à dinâmica atmosférica, não apenas esporadicamente na interpretação de fatos isolados, mas, com a devida ênfase, na própria definição climática regional”, possibilitando assim, a compreensão da gênese dos fenômenos, combinados por diferentes elementos do clima e o seu ritmo de sucessão habitual em um determinado lugar. Assim sendo, diante da necessidade de aperfeiçoamento da classificação genética dos climas regionais, o autor desenvolveu uma técnica denominada "analise rítmica", onde, o ritmo climático passa a ser representado através de gráficos (todos os atributos atmosféricos), revelando a gênese dos fenômenos climáticos e sua interação cronológica no encadeamento dos tipos de tempo, numa escala diária sobre um determinado lugar (MENDONÇA; OLIVEIRA, 2007; MONTEIRO, 1991).

Essa técnica é utilizada em diversos trabalhos acadêmicos na busca de compreensão do complexo climático regional. Sant'Anna Neto (1994) ao estudar a "Dinâmica Atmosférica e o Caráter Transicional do Clima na Zona Costeira Paulista", buscou como objetivo em seu trabalho, rediscutir a dinâmica atmosférica e o caráter transicional do clima nessa área. A metodologia do autor apoiou-se sob o conceito sorreano do clima e na concepção de ritmo climático sob a ótica do método sintético das massas de ar buscando a caracterização do comportamento climático através do regime, ritmo e gêneses das precipitações, a partir de seu padrão habitual, e das suas variações excepcionais. Assim, o autor conclui em seu trabalho, que a gênese pluvial da Zona Costeira Paulista está associada à atividade frontal que Monteiro já havia demonstrado, confirmando a forte influência da sequência de frontogênese na produção de chuvas na região. $\mathrm{O}$ estudo comprovou que a época das chuvas se dá no período primavera-verão, quando o número de passagens frontais aumenta e o fluxo polar é mais intenso. 
XVII Simpósio Brasileiro

de Geografia Fisica Aplicada

I Congresso Nacional

de Geografia Física
OS DESAFIOS DA GEOGRAFIA FÍSICA NA FRONTEIRA DO CONHECIMENTO

Instituto de Geociências - Unicamp

Campinas - SP

28 de Junho à 02 de Julho de 2017

Nessa linha, Ogashawara (2012) estudou a "Análise Rítmica e a Climatologia Geográfica Brasileira” com o objetivo de enfatizar o uso da técnica de análise rítmica para os estudos ambientais, destacando duas ferramentas de auxilio à classificação dos tipos de tempos: as imagens de satélites e as cartas sinóticas. Segundo concluiu, a abordagem rítmica e dinâmica do clima introduzida pela climatologia geográfica brasileira possibilita o entendimento da relação entre os fenômenos ocorrentes na atmosfera permitindo a compreensão da sua relação com a superfície, ressaltando ser indispensável a utilização de ferramentas auxiliares para a classificação dos tipos de tempo e obtenção de maior precisão para o entendimento da dinâmica atmosférica local.

Cunha e Vecchia (2007), bem como Barros e Zavattini (2009), também trouxeram contribuição à questão através das revisões bibliográficas que elaboraram discutindo as bases conceituais da climatologia geográfica, desenvolvendo uma reflexão crítica das duas abordagens (clássica e dinâmica), concluindo que ambas proporcionaram avanços ao entendimento da temática com maior destaque para a climatologia dinâmica, reconhecendo que por mais adequados que possam parecer sozinhas, são incapazes de desvendar o complexo climático de um dado espaço geográfico. Destacando essa importância Sant'Anna Neto (2008, p. 59), menciona que “(...) a concepção geográfica do clima (...) deve ser vista, fundamentalmente, como a geradora de tipos de tempo cujas características são absolutamente dinâmica, complexa e muito sensível a qualquer alteração imposta, influenciando cada parte do planeta (...).”

\section{3. Área de Estudo}

O estudo foi desenvolvido no contexto de São Carlos/SP (Figura 1) utilizando os dados das estações climatológicas situadas na UFSCar (INMET), Embrapa (idem,) e, no município de Itirapina/SP, no CRHEA da EESC/USP. Segundo a classificação de Monteiro (1973), a área está inserida na porção do Estado de São Paulo onde a dinâmica das massas de ar é qualificada como região de climas controlados por massas equatoriais e tropicais com períodos secos e úmidos; com períodos secos distribuídos pelos meses de abril a setembro e úmidos no período de outubro a março (Figura 2).

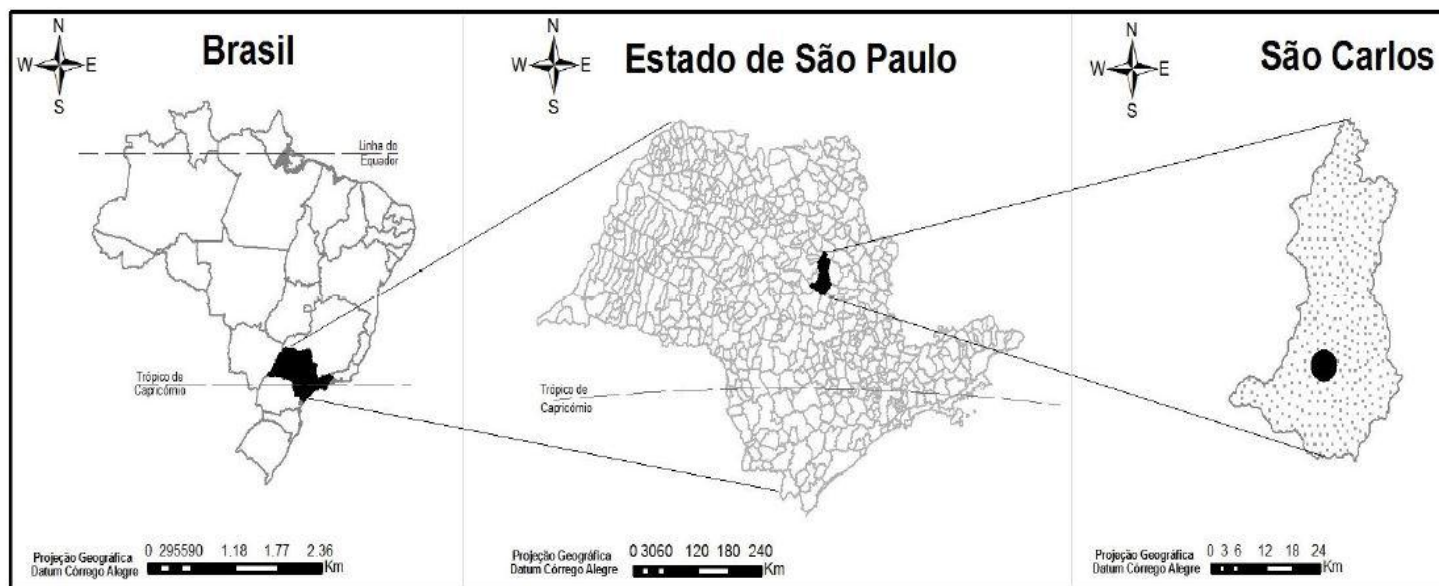

DOI - 10.20396/sbgfa.v1i2017.2418 - ISBN 978-85-85369-16-3 
XVII Simpósio Brasileiro

de Geografia Física Aplicada

I Congresso Nacional

de Geografia Física
OS DESAFIOS DA GEOGRAFIA FÍSICA NA FRONTEIRA DO CONHECIMENTO

Instituto de Geociências - Unicamp

Campinas - SP

28 de Junho à 02 de Julho de 2017

Figura 1: Localização da região de São Carlos

Fonte: Neves (2014, p.41)

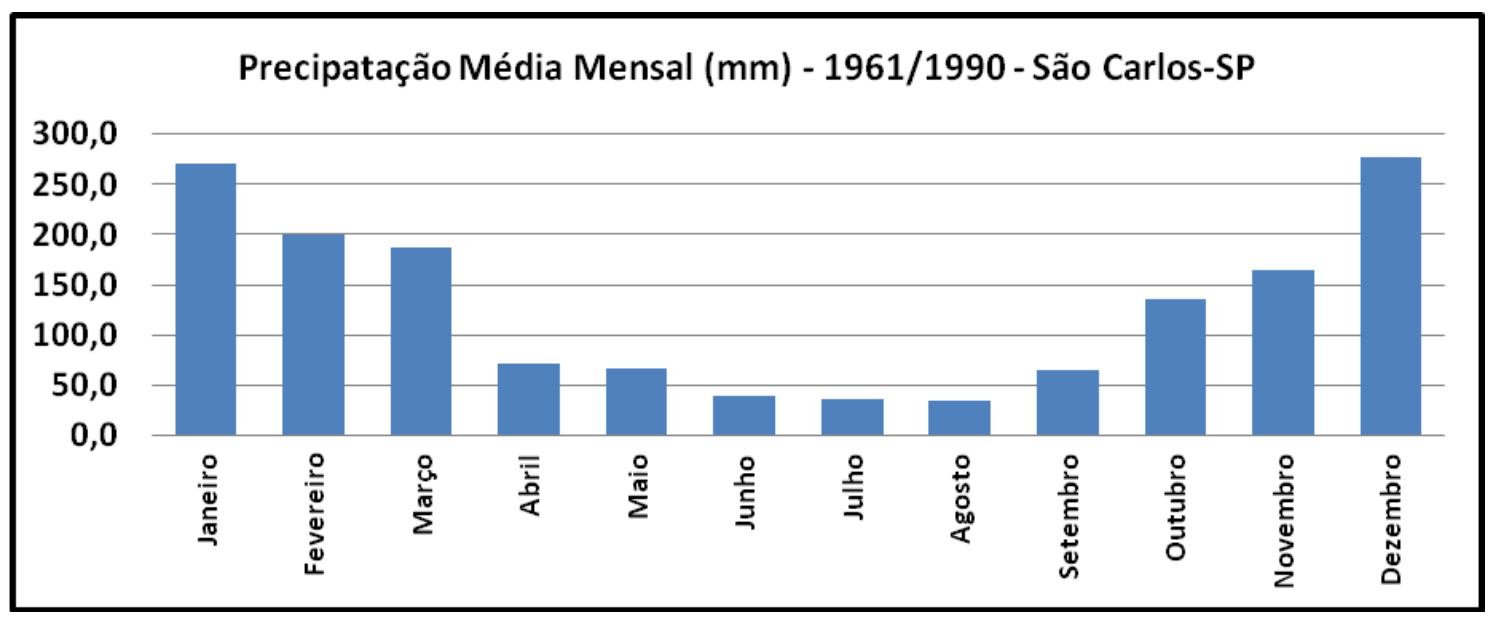

Figura 2: Precipitação mensal de São Carlos segundo as Normais Climatológicas (1961/1990)

Fonte: adaptado de Instituto Nacional de Meteorologia - INMET (2017)

\section{Materiais e Procedimentos Metodológicos}

Para a análise e caracterização dos dados climatológicos foi utilizado o seu tratamento quantitativo, os quais foram colhidos junto ao conjunto de estações climatológicas (Figura 3).

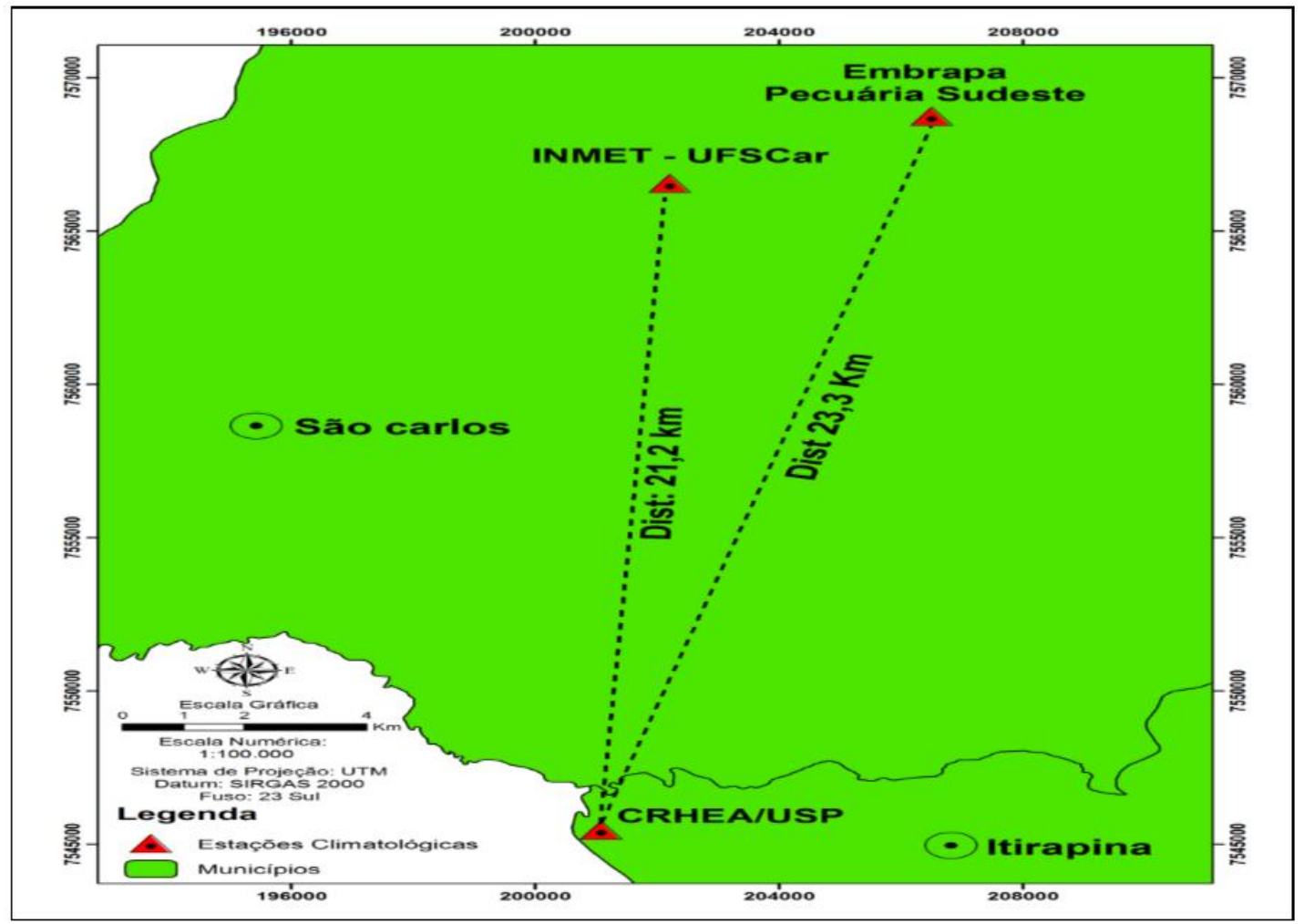


Figura 3: Localização das estações climatológicas

Fonte: Sanches (2015, p.66)

\subsection{Outros Materiais}

Além dos dados que descrevem os índices de algumas variáveis climatológicas, foram necessárias ao estudo as informações concernentes à circulação atmosférica no período. Neste caso, recorreu-se ao conteúdo fornecido pelas cartas sinóticas que são lançadas diariamente pela Divisão de Previsão Ambientais do Centro de Hidrografia da Marinha do Brasil e pelo INPE (00TMG, 06TMG, 12TMG e 18TMG). Também foram utilizadas imagens de satélites para monitoramento da movimentação atmosférica, por meio de imagem negativa das nuvens na superfície terrestre. A partir da sua interpretação é possível descrever a entrada de frentes e de massas atuantes diariamente, sendo elas de Alta ou Baixa pressão (satélite geoestacionário GOES-13 no canal Infravermelho 4). Obviamente boletins como CLIMANÁLISE, INFOCLIMA e PROGCLIMA serviram de apoio assim como as demais publicações da área que se encontram à disposição para consulta.

\subsection{Métodos}

A base metodológica utilizada explorou o conceito da dinâmica do clima e dos "anos padrões" elaborado por Monteiro (1971), onde o critério para caracterização do período é classificado a partir dos anos extremos (seco ou chuvoso), anos habituais e anos tendentes a secos ou a chuvosos. De acordo com esses critérios, os dados climatológicos de pluviosidade foram analisados diariamente, semelhantes aos estados atmosféricos e não apenas pelas médias, de modo a evitar que algum evento atmosférico pudesse ser desconsiderado por estar mascarado pelas médias. Por meio desta análise, foi compreendido o comportamento atmosférico sazonal (escala mesoclimática) do período e, assim, delineou seu ritmo, sua realidade e compreensão na escala local (microclimática). Para a caracterização da atuação da atmosfera na escala mesoclimática, foram consideradas as principais massas de ar e sistemas atmosféricos que atuam no Centro-Sul do Brasil (NIMER 1979; VAREJÃO-SILVA, 2000).

Esta metodologia foi utilizada com êxito em alguns trabalhos (ARMANI; GALVANI, 2011; BORSATO; MENDONÇA, 2013), com objetivo de quantificar e caracterizar o ritmo dos sistemas atmosféricos, por meio de coletas de dados climatológicos e de cartas sinóticas diariamente, contribuindo de maneira a ampliar o conhecimento da dinâmica atmosférica e demonstrar a eficiência que essa metodologia proporciona na compreensão do ritmo e na sucessão dos tipos de tempo no espaço geográfico. Após isto, foi utilizada a metodologia dos "anos padrões" a partir das séries históricas das estações climatológicas de modo a classificar e caracterizar o comportamento pluviométrico em escalas temporais: sazonal, mensal, diária e episódica. Essa caracterização representa "os diferentes graus de proximidade do ritmo "habitual" 


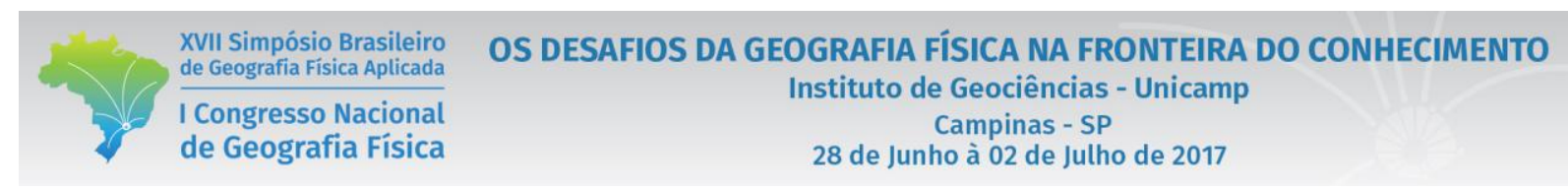

ao lado daqueles afetados por irregularidades na circulação (MONTEIRO, 1991, p.38)”. Portanto, o período de análise correspondente foi de aproximadamente 30 anos de dados, para cada estação climatológica e numa escala sazonal (primavera/verão), estabelecendo assim, os padrões habituais e excepcionais, obtido pelo total pluviométrico médio mensal e do desvio-padrão, que estabelece categorias qualitativas para o comportamento da precipitação do período e na classificação dos anos extremos, de acordo com a Tabela I.

Tabela I: Classificação do padrão pluviométrico com Desvios (+) ou (-) em \%

\begin{tabular}{|l|c|c|}
\hline Anos Normais & desvios variando de & $+15 \% \mathrm{e}-15 \%$ \\
\hline Tendentes a Secos & desvios negativos entre & $-15 \% \mathrm{a}-30 \%$ \\
\hline Anos Secos & desvios negativos superiores & $-30 \%$ \\
\hline Tendentes a Chuvosos & desvios positivos entre & $+15 \% \mathrm{a}+30 \%$ \\
\hline Anos Chuvosos & desvios positivos superiores & $+30 \%$ \\
\hline
\end{tabular}

Fonte: adaptado de Monteiro (1976)

\section{Resultados Obtidos}

Optou-se em começar pela estação com maior tempo de registro (CRHEA/USP), onde foi possível observar como a variabilidade das chuvas se comportou ao longo dos últimos 34 anos. A média calculada para o semestre (outubro a março), dentro do período considerado foi de 1.177,38 mm. Após o calculo da média foram realizados cálculos estatísticos, como o desvio da média e coeficiente de variação, observando que houve uma variabilidade no comportamento pluviométrico do período como é demonstrado na Figura 4.

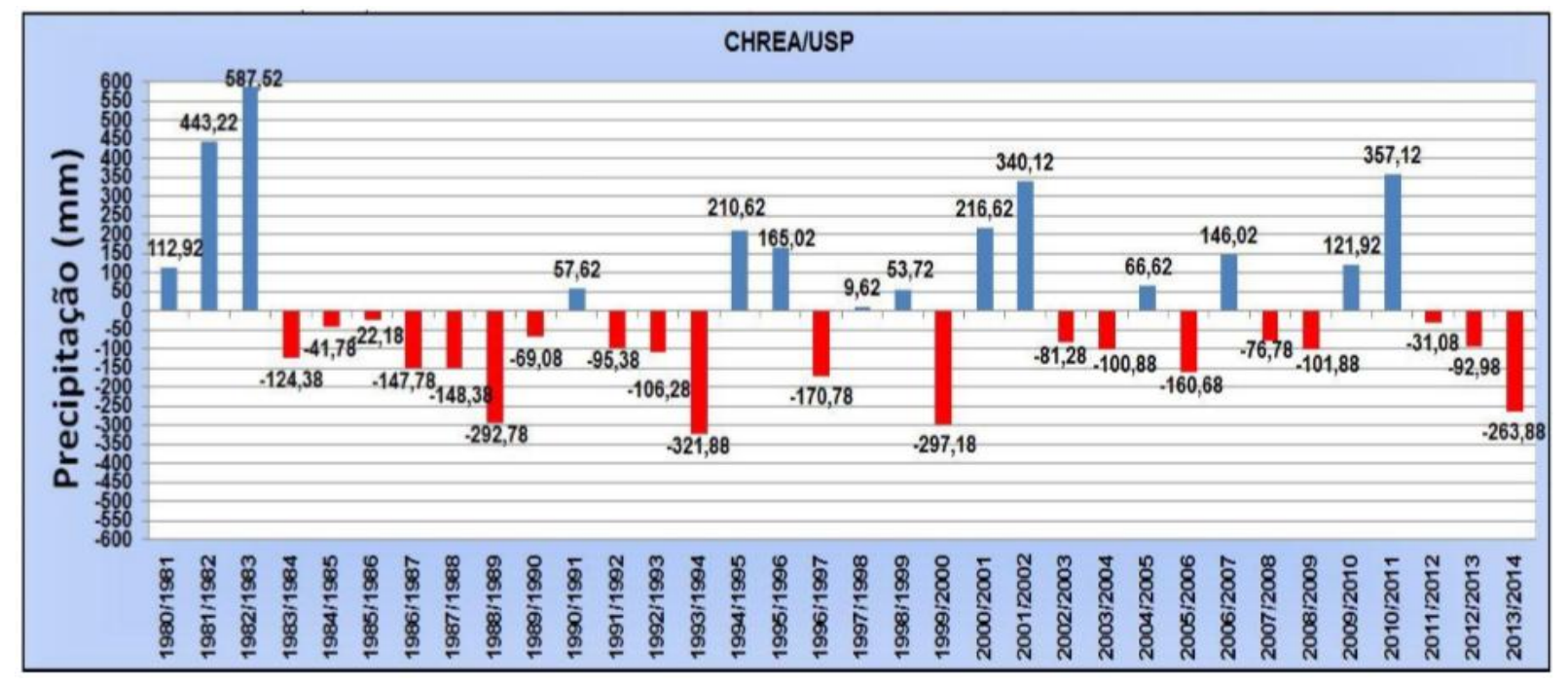

Figura 4: Desvio da média de precipitação do período de 1980/81 - 2013/14 - Estação CRHEA/USP 
Analisando os dados pode-se observar que a ordem de frequência com maior ocorrência foram os semestres que apresentaram valores de precipitação com desvios variando entre $-15 \%$ e $+15 \%$ e classificando como semestres Normais $(\mathrm{N})$. O número de ocorrências de semestres dentro dessa classificação foi de 24 vezes, e representando percentualmente 70,58\% do total. A segunda maior ordem de ocorrência foram os semestres que apresentaram valores com desvios negativos na precipitação variando entre $-15 \%$ e $-30 \%$ e classificando como "Tendente a Seco" (Ts) com um total de 4 vezes, e assim, representando percentualmente $11,76 \%$; e, por último a terceira maior ordem de frequência ficou dividida entre os semestres que apresentaram valores com desvios positivos variando entre $+15 \%$ e $+30 \%$ e superiores que $+30 \%$ e, classificando como "Tendente a Chuvoso" (Ts) e "Chuvosos" (C) com um total respectivo de 3 vezes cada representando percentualmente $8,82 \%$ do total.

A estação INMET/UFSCar apresenta a segunda maior série histórica da análise, possuindo dados referentes a um período de 28 anos. A média para o período do semestre chuvoso foi um valor de 1.211 mm. Nessa estação, também foi possível identificar ao longo da série histórica uma variabilidade das chuvas em relação à média (Figura 5).

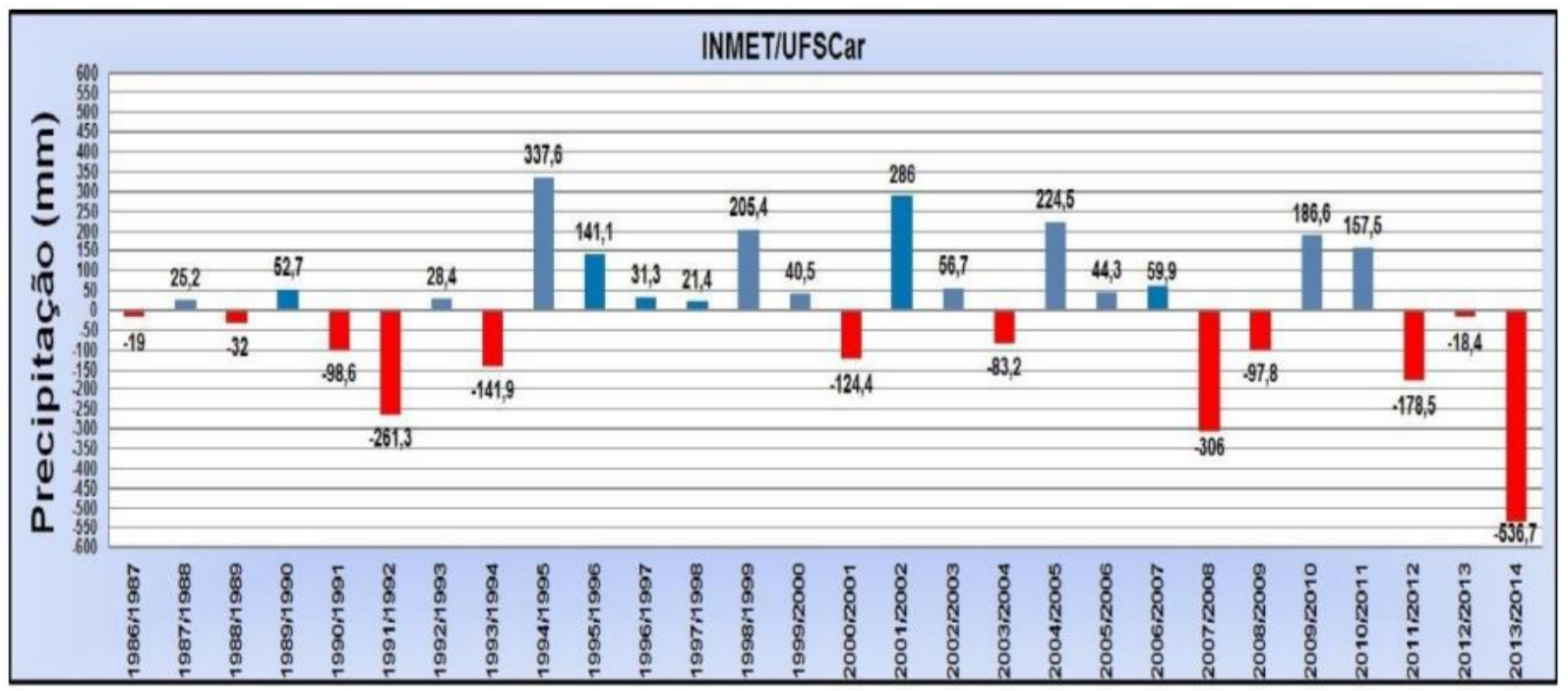

Figura 5: Desvio da média de precipitação do período de 1986/87 - 2013/14 - Estação INMET/USFCar

Observa-se que a maior ocorrência de frequência ao longo da série de 1986/1987 a 2013/2014 foi de semestres "Normais" (N) com 20 vezes representando 71,42\% do total, seguido pelos que apresentaram valores com desvios positivos variando entre $+15 \%$ e $+30 \%$ e classificados como "Tendente a Chuvoso" (Tc), com um total de 4 ocorrências alcançando 14,2\% das ocorrências das chuvas, vindo a seguir os semestres com desvios negativos entre $-15 \%$ e $-30 \%$ e classificados como "Tendentes a Seco" (Ts) com um total de 2 manifestações respondendo por 7,1\%. Por último vem com uma ocorrência apenas cada um 


\section{OS DESAFIOS DA GEOGRAFIA FÍSICA NA FRONTEIRA DO CONHECIMENTO \\ Instituto de Geociências - Unicamp \\ Campinas - SP \\ 28 de Junho à 02 de Julho de 2017}

os semestres "Chuvoso" e "Seco". Por último, a quarta maior ordem de frequência ficou dividida entre as classificações Chuvoso (C) e Seco (S), com uma ocorrência cada correspondendo a 3,5\% do total.

A estação EMBRAPA/Sudeste apresenta a menor série histórica com um período de 21 anos. A média para o período do semestre chuvoso foi de $1.129 \mathrm{~mm}$. Como as demais estações, foi possível identificar ao longo da série histórica uma variabilidade das chuvas em relação à média (Figura 6).

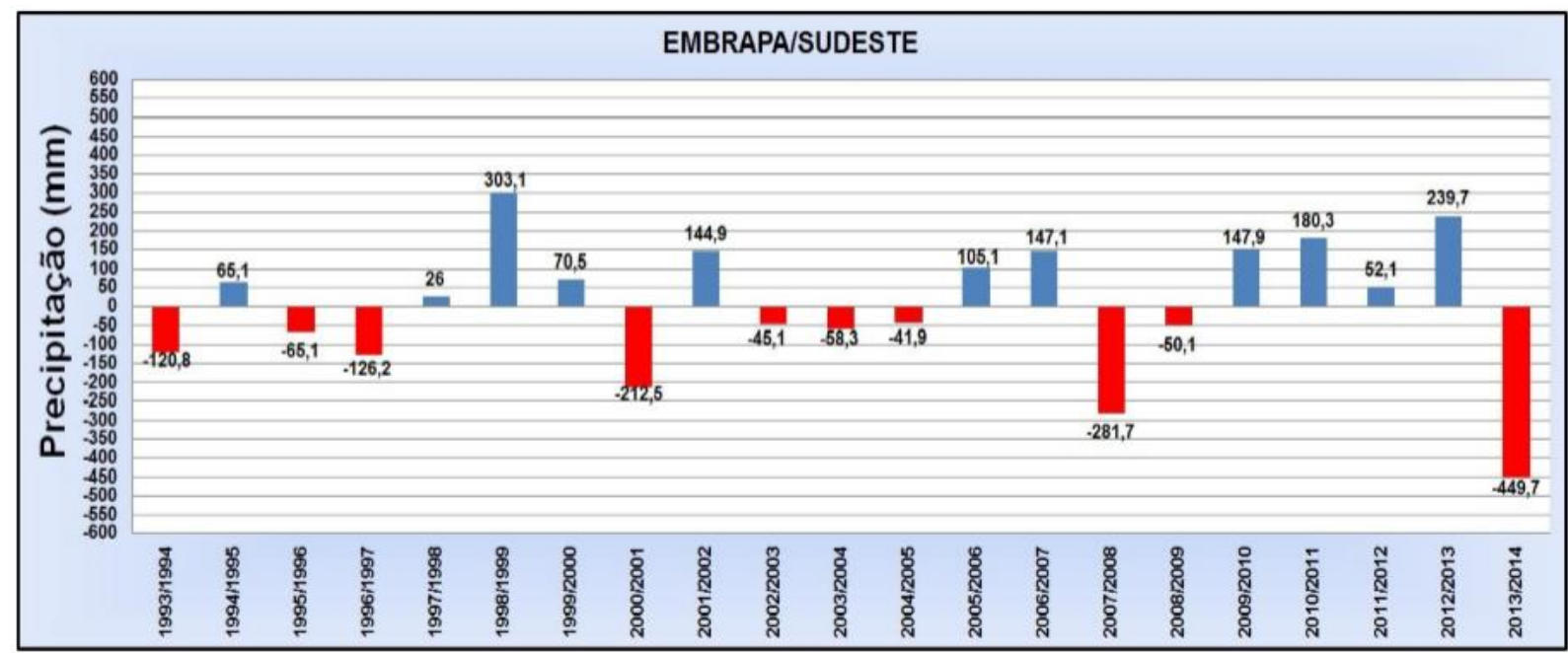

Figura 6: Desvio da média de precipitação período 1993/94-2013/14 - Estação EMBRAPA/SUDESTE

Nela, o número de ocorrência com maior ordem de frequência também ficou dentro dos valores dos desvios variando entre $-15 \%$ a $+15 \%$ e classificando como semestres Normais $(\mathrm{N})$, e representando percentualmente $71,4 \%$ do total. Após isso, a segunda maior ordem de frequência ficou dividida entre 2 vezes na classificação como Tendente a Chuvoso (Tc) e 2 vezes como "Tendente a Seco" (Ts), representando percentualmente $9,5 \%$ cada um dos eventos. Por último a terceira ordem de frequência ficou também dividida entre "Chuvoso" (C) e "Seco" (S), correspondendo percentualmente 4,7\% cada um dos eventos para toda série histórica de 21 anos com uma única ocorrência cada.

Pelo que se pode observar nos dados colhidos, a estação do CRHEA/USP registrou no período chuvoso de 2013/2014 um total de 913,5 mm e, apresentou valores com desvio negativo na precipitação classificando como "Tendente a Seco" (Ts); já a estação do INMET/USFCar registrou no mesmo período um total de $674,2 \mathrm{~mm}$, apresentando valores com desvios negativos na precipitação e classificando como Seco (S); enquanto que a estação da EMBRAPA/Sudeste acusou total de 679,2 $\mathrm{mm}$ situando-se também na condição de semestre Seco (S).

Diante disto, fica claro que o semestre letivo estudado apresentou um perfil fora da média histórica obtida no cálculo dos Anos Padrões da série considerada, confirmando que o padrão atmosférico da área nesse 
período também não apresentou a habitualidade esperada que proporciona maior umidade para a região em questão a partir das contribuições trazidas pelas frentes (advindas do Atlântico Sul e surgidas nas imediações da Patagônia argentina) e da umidade amazônica (transportada pela Zona de Convergência do Atlântico Sul) devido aos bloqueios atmosféricos que se estabeleceram dificultando a movimentação das massas de ar que rotineiramente agem nessa época do ano.

Se essa configuração atmosférica tornar-se habitual a partir de um reordenamento dos sistemas produtores de vento no planeta, o clima da área sofrerá mudanças sensíveis que acarretarão sérios impactos, pois mesmo na estação do CRHEA/USP fez-se sentir de forma considerável a diminuição no input de umidade, não obstante o percentual extra que recebe das chuvas orográficas devido a localização que possui (dado que estimula novos projetos de pesquisa dedicados a mensuração do papel da orografia na nível de precipitação das "cuestas basálticas" e áreas similares formando "ilhas de umidade" na paisagem).

\section{Considerações Finais}

Pelo que se pode observar, os sistemas atmosféricos no período chuvoso de 2013/2014 não se comportaram dentro dos parâmetros dos últimos doze anos, sem, contudo, distanciar-se da sazonalidade identificada na série temporal analisada (1980-2014), atestando, por conseguinte, todo cuidado que deve existir quando se procura associar tais situações a um quadro maior de mudanças climáticas ou instabilidades. Aliás, toda a habitualidade do período atesta que tais situações são recorrentes e configuram um padrão atmosférico muito bem estabelecido.

Obviamente a contemporaneidade e todos os discursos ideológicos estimulam o recorte do período chuvoso de 2013/2014 de sua série histórica com o intuito de organizar argumentos e dados compatíveis com o discurso em defesa do advento de uma nova era de instabilidade e reordenamento de energia no sistema oceano-atmosfera a partir da adoção dos mais diversos paradigmas que permeiam essa área do conhecimento a partir das linhas e interpretações qexistentes.

Pelo que se pode observar nos dados coletados nas três estações consultadas, tem-se na série histórica uma média aproximada de 71,5\% de Anos Normais onde o índice pluviométrico ficou muito próximo ou igual a média da série histórica, de 7,1\% a 11,7\% de Anos Tendentes a Seco, de 8,8\% a 14,2\% Anos Tendentes a Chuvoso, de 3,5\% a 8,8\% Anos Chuvosos, e, 3,5\% a 4,7\% de Anos Secos.

De posse desses dados é possível afirmar que a habitualidade do padrão atmosférico que prevalece na área de estudo transita em patamares que dificilmente impõe uma carência na oferta de água.

Além disso, tem-se ainda a informação concreta de que os índices pluviométricos anotados no período estudado de outubro de 2013 a março de 2014 foram os mais expressivos da série, porém houve períodos 
negativamente em relação à média anotada em mais de uma vez. Assim, fica difícil aceitar o discurso dos dirigentes políticos dos diferentes Entes Federativos (Municípios, Estados e União) afirmando que racionamento de água é consequência do índice pluviométrico, pois, em alguns outros anos a recarga proporcionada pelas chuvas à rede hidrográfica foi menor e naquelas ocasiões não se acusou problemas no abastecimento.

Pelo que se observa, inexiste política pública de planejamento que esteja reconfigurando a infraestrutura de abastecimento (coleta, tratamento, armazenamento e distribuição) para o aumento na demanda ou períodos com menor precipitação, pois a tônica tem sido desviar as empresas de abastecimento do controle do Estado para a posse da iniciativa privada.

Em São Carlos onde o sistema de abastecimento é mantido em poder da sociedade local através da Prefeitura Municipal, esse período de menor precipitação foi atravessado sem suspensão das atividades econômicas ou racionamento de água, assim como em Engenheiro Coelho/SP ou Poços de Caldas/MG (distante respectivamente cerca de 100 e 170 km) onde o Poder Público local também mantém o controle da empresa responsável pelo abastecimento de água. Todavia, nas cidades ao redor que são atendidas pela Sabesp verificou-se cortes no abastecimento de água, denunciando a todos que onde o abastecimento de água não está a serviço da geração de dividendos para acionistas privados, o investimento na melhoria do sistema é feito em benefício da população, amenizando a diminuição que se observa no suprimento de água nos momentos em que a sazonalidade manifesta um padrão atmosférico com menor incidência de chuvas, pois, dado ao volume precipitado nesses períodos ainda é possível atender as demandas da população sem prejuízo de sua qualidade de vida.

\section{Bibliografia}

BARROS, J. R.; ZAVATTINI, J. A. Bases conceituais em climatologia geográfica. Mercator - Revista de Geografia da UFC, Fortaleza, v. 8, n. 16, p. 255-261, maio/ago. 2009.

BORSATO, V. A. A Climatologia dinâmica e o ensino da geografia no segundo grau: uma aproximação ao problema. Revista GeoNotas, Maringá, v. 4, n. 1, 2000.

BORSATO, V. A.; MENDONÇA, F. A. A Dinâmica dos sistemas atmosféricos no verão 2012-2013 no Paraná e em Campo Mourão. In: SIMPÓSIO DE ESTUDOS URBANOS: a dinâmica das cidades e a produção do espaço, 2., 2013, Campo Mourão. Anais... Campo Mourão: UEP, 2013. p. 1-30.

CENTRO DE PREVISÃO DO TEMPO E ESTUdOS CLIMÁTICOS. Análise sinótica. Cachoeira Paulista, 2014. Disponível em: $<$ http://www.cptec.inpe.br/noticias/faces/noticias.jsp?idConsulta=\&idQuadros=14 2>. Acesso em: 18 nov. 2014.

CUNHA, D. G. F.; VECCHIA, F. As Abordagens clássica e dinâmica de clima: uma revisão bibliográfica aplicada ao tema da compreensão da realidade climática. Ciência e Natura, Santa Maria, v. 29, n. 1, p. 137-149, 2007.

FRANCA, R. R. Chuvas extremas e inundações na Bolívia no verão 2013/2014. In: SIMPÓSIO BRASILEIRO DE CLIMATOLOGIA GEOGRÁFICA, 10., 2014, Curitiba. Anais... Curitiba: [s.n.], 2014. p. 1545-1555. 
GABRIEL, G. H.; NUNES, L. H. Mudanças temporais e espaciais nos padrões de distribuição pluviométrica no estado de São Paulo, Brasil. In: SIMPÓSIO BRASILEIRO DE CLIMATOLOGIA GEOGRÁFICA, 10., 2014, Curitiba. Anais... Curitiba: [s.n.], 2014. p. 1565-1576.

GIRÃO, O.; CORRÊA, A. C. B.; GUERRA, A. J. T. Influência da climatologia rítmica sobre áreas de risco: o caso da região metropolitana do Recife para os anos de 2000 e 2001. Revista de Geografia, Recife, v. 23, n.1, p. 3-40, 2006.

INSTITUTO NACIONAL DE METEOROLOGIA. Normais climatológicas de precipitação 1960-1990. Brasília, 2014. Disponível em:<http://www.inmet.gov.br/portal/index.php?r=clima/normaisClimatologicas>. Acesso em: 18 nov. 2014

MENDONÇA, F.; DANNI-OLIVEIRA, I. M. Climatologia: noções básicas e climas do Brasil. São Paulo: Oficina de Textos, 2007. p. 206.

MONTEIRO, C. A. F. Da Necessidade de um caráter genético à classificação climática (algumas considerações metodológicas a propósito do estudo do Brasil meridional). Revista Geográfica, Rio de Janeiro, v. 31, n. 57, p. 2944, 1962.

Análise rítmica em climatologia: problemas da atualidade climática em São Paulo e achegas para um programa de trabalho. São Paulo: USP, 1971.

de atlas. São Paulo: IG/USP, 1973.

Dinâmica climática e as chuvas no estado de São Paulo. Estudo geográfico sob forma O Clima e a organização do espaço no estado de São Paulo: problemas e perspectivas. São Paulo: IGEOG/USP, 1976. (Série Teses e Monografias, 28).

Clima e excepcionalidade: conjunturas sobre o desempenho da atmosfera como fenômeno climático. Florianópolis: UFSC, 1991.

NEVES, G. Z. F. Variabilidade da radiação em ondas longas em uma cidade de porte médio: experimentos nos espaços livres em São Carlos- SP. 2014. Dissertação (Mestrado em Ciências da Engenharia Ambiental) Escola de Engenharia de São Carlos, Universidade de São Paulo, São Carlos, 2014.

NIMER, E. Climatologia do Brasil. Rio de Janeiro: IBGE, 1979.

OGASHAWARA, I. Análise rítmica e a climatologia geográfica brasileira. Revista Geoaraguaia, Barra do Garças, v.2, n.2, p. 57-72, ago./dez. 2012.

SANCHES, R. G. Análise das chuvas na região de São Carlos/SP: o entendimento e o comportamento pluviométrico a partir de estações climatológicas, 1993-2014. 2015. Dissertação (mestrado) - Escola de Engenharia de São Carlos, Universidade de São Paulo, São Carlos, 2015.

SANT'ANNA NETO, J. L. Dinâmica atmosférica e o caráter transicional do clima na zona costeira paulista. Revista do Departamento de Geografia, São Paulo, v. 8, p. 29-34, 1994.

Da Climatologia geográfica à geografia do clima: gênese, paradigmas e aplicações do clima como fenômeno geográfico. Revista da ANPEGE, n.4, p. 51- 72, 2008.

SANTOS, J. W. M. C. - Rítmo Climático e Sustentabilidade Sócio-Ambiental da agricultura comercial da soja no Sudeste de Mato Grosso. Revista do Departamento de Geografia (USP), v. 1, nº especial, p. 01 - 20, 2005 ;

SILVEIRA, L. M. Os Sistemas atmosféricos e a variação do tempo em Maringá, estado do Paraná, Brasil. Acta Scientiarun Technology, Maringá, v.28, n.1, p. 7984, jan./jun. 2006.

VAREJÃO-SILVA, M. A. Meteorologia e Climatologia. Brasília: INMET, Stilo, 2000.

WOLlMANN, C. A.; SARTORI, M. G. O Clima do Rio Grande do Sul no verão: análise sobre a circulação atmosférica regional e os principais tipos de sucessão do tempo em três casos típicos. Geografia: ensino \& pesquisa. v. 13, n. 1, p.33-42, 2009.

Agradecimento: Ao CNPq pelo apoio financeiro dispensando ao longo da pesquisa de mestrado que foi desenvolvida. 